\title{
Activity Induced by a Naphthalene-Prazosin Derivative on Ischemia/Reperfusion Injury in Rats
}

\author{
Betty Sarabia-Alcocer ${ }^{1}$, Lauro Figueroa-Valverde ${ }^{*}$, Francisco Díaz-Cedillo², \\ Lenin Hau-Heredia', Marcela Rosas-Nexticapa ${ }^{3}$, Elodia García-Cervera1, \\ Eduardo Pool-Gómez ${ }^{1}$, Rolando García-Martínez ${ }^{4}$, Braulio Zepeda-Acosta ${ }^{1}$ \\ ${ }^{1}$ Laboratory of Pharmaco Chemistry, Faculty of Chemical and Biological Sciences, University Autonomous of \\ Campeche, Campeche, México \\ ${ }^{2}$ Escuela Nacional de Ciencias Biológicas del Instituto Politécnico Nacional, México D.F., México \\ ${ }^{3}$ Facultad de Nutrición, Universidad Veracruzana, Veracruz, México \\ ${ }^{4}$ Laboratorio de Neurociencias del Centro de Investigaciones Biomédicas de la Universidad Autónoma de \\ Campeche, Campeche, México \\ Email: "lauro 1999@yahoo.com
}

Received 9 October 2014; revised 5 November 2014; accepted 25 November 2014

Academic Editor: Ehab S. EL Desoky, Assiut University, Egypt

Copyright (C) 2014 by authors and Scientific Research Publishing Inc.

This work is licensed under the Creative Commons Attribution International License (CC BY).

http://creativecommons.org/licenses/by/4.0/

(c) (i) Open Access

\section{Abstract}

In this study, a new naphthalene-prazosin derivative (compound 5) was synthetized with the objective of evaluating its activity on ischemia/reperfusion injury. The Langendorff technique was used to evaluate the effect of the compound 5 on ischemia/reperfusion injury. Additionally, the mechanism of action involved in the activity exerted by the compound 5 on perfusion pressure and coronary resistance was evaluated by measuring left ventricular pressure in absence or presence of following compounds; prazosin, metoprolol, indomethacin and nifedipine. The results showed that the compound 5 reduced infarct size compared with the control conditions. Other results showed that the compound 5 significantly increases $(p=0.05)$ the perfusion pressure and coronary resistance in isolated rat heart. In addition, other data indicate that the compound 5 increases left ventricular pressure in a dose-dependent manner $(0.001$ to $100 \mathrm{nM})$; however, this phenomenon was significantly inhibited by nifedipine at a dose of $1 \mathrm{nM}(p=0.05)$ and this effect was independent of cAMP levels. In conclusion, these data suggest that the naphthalene-prazosin derivative exerts a cardio protective effect via the calcium channels activation and consequently induces changes in the left ventricular pressure levels. This phenomenon results in a decrease of

${ }^{*}$ Corresponding author. 
myocardial necrosis after ischemia and reperfusion.

Keywords

Prazosin, Left Ventricular Pressure, Nifedipine, Naphthalene

\section{Introduction}

Clinical data indicate that myocardial infarction is a major cause of death and disability worldwide [1] [2]; this cardiovascular disease is due to cell death of cardiac myocytes caused by prolonged myocardial ischemia. Acute myocardial infarction can produce alterations in the topography of both the infarcted and noninfarcted regions of the ventricle [3]. Some reports show that the most effective method of limiting necrosis is restoration of blood flow; however, the effects of reperfusion itself may also be associated with tissue injury [4]. To reduce this phenomenon, a series of drugs have been used; for example, $\mathrm{Na}^{+}-\mathrm{H}^{+}$exchange inhibitors (amiloride) [5], inhibitors of the mitochondrial permeability transition pore (sanglifehrin-A), peptidic delta-opioid agonist (BW373U86 dihydrobromide) [6], erythropoietin [7], Glibenclamide (ATP-regulated $\mathrm{K}^{+}$channels activation) [8] and Cyclosporin A (which reduce the cAMP levels) [9].

On the other hand, some naphthalene derivatives have been developed to evaluate their biological activity in several animal models; for example, a study showed that the naphthalene derivative (( \pm )-(R,S)-5,6-dihy-droxy2-methylamino-1,2,3,4-tetrahydro-naphthalene hydro-chloride) induces protective effects on ischemia/reperfusion injury in isolated heart rat via decrease of norepinephrine [10]. Other report, showed that the naphthalene derivative (N-(6-aminohexyl)-5-chloro-1-naphthalenesulfonamide), exerts cardioprotective effects on the isolated rat heart exposed to hypothermic and ischemic conditions by blocking the activity of calmodulin [11]. Other data indicates that compound 1,5-(dimethylamino)-N-(3,4-dimethyl-5-isoxazolyl)-1-naphthalene sulfonamide, significantly improved the recovery of cardiac function during reperfusion-ischemia injury through of reduced of creatine kinase [12]. All these data indicates that differences in the chemical structure of naphthalene derivatives may be in part responsible of activity of these compounds on ischemia/reperfusion injury. To test this information, the present study was designed to investigate the effects induced by a naphthalene-prazosin derivative in a myocardial infarction/reperfusion model. In order to evaluate the molecular mechanism involved in the activity of the naphthalene-prazosin derivative on left ventricular pressure, some drugs related to ischemic-reperfusion were used as pharmacological tools for blocking various biological systems such as prazosin ( $\alpha_{1}$ adrenoreceptor antagonist) [13], metoprolol (selective $\beta_{1}$ receptor blocker) [14], indomethacin (prostaglandin synthesis inhibitor) [15] and nifedipine (antagonist calcium channel type L) [16].

\section{Experimental}

\subsection{Chemical Synthesis}

All compounds evaluated in this study were purchased from Sigma-Aldrich Co., Ltd. The melting point for the compounds was determined on an Electro thermal (900 model). ${ }^{1} \mathrm{H}$ and ${ }^{13} \mathrm{C}$ NMR (nuclear magnetic resonance) spectra were recorded on a Varian VXR-300/5 FT NMR spectrometer at 300 and $75.4 \mathrm{MHz}$ (megahertz) in $\mathrm{CDCl}_{3}$ (deuterated chloform) using TMS (tetramethylsilane) as internal standard. EIMS (electron impact mass spectroscopy) spectra were obtained with a Finnigan Trace Gas Chromatography Polaris Q Spectrometer. Elementary analysis data were acquired from a Perkin Elmer Ser. II CHNS/0 2400 elemental analyzer.

\subsubsection{Synthesis of N-1-\{[4-Amino-6,7-Dimethoxy-Quinazolin-2-yl)Piperazin-1-yl]- Furan-2-yl-Methylene\}-Ethane-1,2-Diamine (Compound 3)}

A solution of prazosin (100 mg, $0.26 \mathrm{mmol})$, ethylenedimine $(50 \mu \mathrm{l}, 0.74 \mathrm{mmol})$ ) and boric acid $(40 \mathrm{mg}, 0.65$ $\mathrm{mmol}$ ) in $10 \mathrm{~mL}$ of methanol was stirred for $48 \mathrm{~h}$ at room temperature. The reaction mixture was evaporated to dryness under reduced pressure, the residue washed 3 times with water. Then the precipitate was separated and dried at room temperature. 


\subsubsection{Synthesis of 2-[4-(Furan-2yl-\{2-[(Naphtalen-1-Ylmethylene-Amino]-Ethylimino-Methyl) Piperazin-1-yl]-4-[(Napftalen-1ylmethylene)-Amino-6,7-Dimethoxy-Quinazolin-6,7-Diol (Compound 5)}

A solution of compound 3 (100 mg, $0.23 \mathrm{mmol}$ ), 2-hydroxy-1-naphthaldehyde (compound 4; $40 \mathrm{mg}, 0.23 \mathrm{mmol}$ ) and boric acid ( $40 \mathrm{mg}, 0.65 \mathrm{mmol}$ ) in $10 \mathrm{~mL}$ of methanol was stirred for $48 \mathrm{~h}$ at room temperature. The reaction mixture was evaporated to dryness under reduced pressure, the residue washed 4 times with water. Then the precipitate was separated and dried at room temperature.

\subsection{Biological Method}

All experimental procedures and protocols used in this investigation were reviewed and approved by the Animal care and use Committee of University Autonomous of Campeche (No. PI-420/12) and were in accordance with the guide for the care and use of laboratory animals [17]. Male Wistar rats; weighing 200 - $250 \mathrm{~g}$ were obtained from University Autonomous of Campeche.

\subsection{Reagents}

All drugs were dissolved in methanol and different dilutions were obtained using Krebs-Henseleit solution $(\leq$ $0.01 \%, \mathrm{v} / \mathrm{v})$.

\subsection{Experimental Design}

Briefly, the male rat (200 - 250 g) was anesthetized by injecting them with pentobarbital at a dose rate of 50 $\mathrm{mg} / \mathrm{Kg}$ body weight. Then the chest was opened, and a loose ligature passed through the ascending aorta. The heart was then rapidly removed and immersed in ice cold physiologic saline solution. The heart was trimmed of non-cardiac tissue and retrograde perfused via a non-circulating perfusion system at a constant flow rate. The perfusion medium was the Krebs-Henseleit solution $\left(\mathrm{pH}=7.4,37^{\circ} \mathrm{C}\right)$ composed of (mmol); $117.8 \mathrm{NaCl}$; $6 \mathrm{KCl}$; $1.75 \mathrm{CaCl}_{2} ; 1.2 \mathrm{NaH}_{2} \mathrm{PO}_{4} ; 1.2 \mathrm{MgSO}_{4} ; 24.2 \mathrm{NaHCO}_{3} ; 5$ glucose and 5 sodium pyruvate. The solution was actively bubbled with a mixture of $\mathrm{O}_{2} / \mathrm{CO}_{2}(95: 5 / 5 \%)$. The coronary flow was adjusted with a variable speed peristaltic pump. An initial perfusion rate of $15 \mathrm{ml} / \mathrm{min}$ for $5 \mathrm{~min}$ was followed by a 15 min equilibration period at a perfusion rate of $10 \mathrm{ml} / \mathrm{min}$. All experimental measurements were done after this equilibration period.

\subsection{Perfusion Pressure}

Evaluation of measurements of perfusion pressure changes induced by drugs administration in this study were assessed using a pressure transducer connected to the chamber where the hearts were mounted and the results entered into a computerized data capture system (Biopac).

\subsection{Inotropic Activity}

Contractile function was assessed by measuring left ventricular developed pressure (LV/dP), using a salinefilled latex balloon $(0.01 \mathrm{~mm}$, diameter) inserted into the left ventricle via the left atrium [18]. The latex balloon was bound to cannula which was linked to pressure transducer that was connected with the MP100 data acquisition system.

\section{First Stage \\ Ischemia/Reperfusion Model}

After of 15-minute equilibration time, the hearts were subjected to ischemia for 30 minutes by turning off the perfusion system [19]. After this period, the system was restarted and the hearts were reperfused by 30 minutes with Krebs-Henseleit solution. The hearts were randomly divided into 2 major treatment groups with $\mathrm{n}=9$ :

Group I. Hearts were subjected to ischemia/reperfusion but received vehicle only (Krebs-Henseleit solution).

Group II. Hearts were subjected to ischemia/reperfusion and treated with the compound 5 (0.001 nM) before ischemia period (for 10 minutes) and during the entire period of reperfusion. At the end of each experiment, the perfusion pump was stopped, and $0.5 \mathrm{ml}$ of fluorescein solution $(0.10 \%)$ was injected slowly through a sidearm 
port connected to the aortic cannula. The dye was passed through the heart for $10 \mathrm{sec}$ to ensure its uniform tissue distribution. The presence of fluorescein was used to demarcate the tissue that was not subjected to regional ischemia, as opposed to the risk region. The heart was removed from the perfusion apparatus and cut into two transverse sections at right angles to the vertical axis. The right ventricle, apex, and atrial tissue were discarded. The areas of the normal left ventricle non risk region, area at risk, and infarct region were determined using methods previously reported [19]. Total area at risk was expressed as the percentage of the left ventricle.

\section{Second Stage}

Effect induced by the compounds 3, 4, 5 and prazosinon perfusion pressure: Changes in perfusion pressure as a consequence of increases in time (3 to $18 \mathrm{~min}$ ) in absence (control) or presence of the compounds 3, 4, 5 and prazosin on perfusion pressureat a concentration of $0.001 \mathrm{nM}$ were determined. The effects were obtained in isolated hearts perfused at a constant-flow rate of $10 \mathrm{ml} / \mathrm{min}(\mathrm{n}=9)$.

Evaluation of effects exerted by the compounds 3, 4, 5 and prazosin on coronary resistance: The coronary resistance in absence (control) or presence of the compounds 3, 4, 5 and prazosin at a concentration of $0.001 \mathrm{nM}$ was evaluated. The effects were obtained in isolated hearts perfused at a constant flow rate of $10 \mathrm{ml} / \mathrm{min}$. Since a constant flow was used changes in coronary pressure reflected the changes in coronary resistance $(n=9)$.

\section{Third Stage}

Effects induced by the compound $\mathbf{5}$ on left ventricular pressure through $\alpha_{1}$-adrenergic receptor. Intracoronary boluses $(50 \mu \mathrm{l})$ of the compound $5(0.001$ to $100 \mathrm{nM})$ were administered and the corresponding effect on the left ventricular pressure was determined. The dose-response curve (control) was repeated in the presence of prazosin at a concentration of $1 \mathrm{nM}$ (duration of preincubation with prazosin was by a 10 min equilibration period, $\mathrm{n}=9$ ).

Effects induced by the compound 5 on left ventricular pressure through $\beta_{1}$-adrenergic receptor. Intracoronary boluses $(50 \mu \mathrm{l})$ of the compound $5(0.001$ to $100 \mathrm{nM})$ were administered and the corresponding effect on the left ventricular pressure was determined. The dose-response curve (control) was repeated in the presence of metoprolol at a concentration of $1 \mathrm{nM}$ (duration of preincubation with metoprolol was by a 10 min equilibration period, $\mathrm{n}=9$ ).

Effect exerted by the compound 5 on left ventricular pressure in the presence of indomethacin. The boluses $(50 \mu \mathrm{l})$ of the compound 5 [0.001 to $100 \mathrm{nM}$ ] were administered and the corresponding effect on the left ventricular pressure was evaluated. The bolus injection administered was done in the point of cannulation. The dose response curve (control) was repeated in the presence of indomethacin at a concentration of $1 \mathrm{nM}$ (duration of the pre-incubation with indomethacin was for a period of $10 \min \mathrm{n}=9$ ).

Effects of the compound $\mathbf{5}$ on left ventricular pressure through the calcium channel activation: Intracoronary boluses $(50 \mu \mathrm{l})$ of the compound $5[0.001$ to $100 \mathrm{nM}]$ were administered and the corresponding effect on the left ventricular pressure was evaluated. The dose-response curve (control) was repeated in the presence of nifedipine at a concentration of $1 \mathrm{nM}$ (duration of the pre-incubation with nifedipine was for a period of $10 \mathrm{~min} n=9$ ). It is important to mention that the doses evaluated of inhibitors for prostaglandins, $\alpha_{1}$ and $\beta_{1}$-adrenergic receptor have been previously reported [20].

\subsection{Effect of the Compound 5 on cAMP Levels}

The hearts $(\mathrm{n}=9)$ were perfused with compound $5(1 \mathrm{mmol})$ and vehicle (control) for 2 , 5, or 30 minutes. After the appropriate period of infusion, atrial tissue was removed, and the ventricles were immediately frozen with liquid nitrogen and stored at $270^{\circ} \mathrm{C}$ until assayed. Tissue samples were homogenized with $6 \%$ trichloroacetic acid at $4^{\circ} \mathrm{C}$ to give a $10 \%(\mathrm{w} / \mathrm{v})$ homogenate, followed by centrifugation at $2000 \mathrm{rpm}$ (Hettich Zentrifugen, EBA-270) for 15 minutes. Then supernatants were collected and washed with water:diethyl ether $(5: 1 \mathrm{v} / \mathrm{v})$ five times. The extracts were lyophilized and processed for the measurement of cAMP content by use of a standard ${ }^{125}$ I radioimmunoassay kit supplied by Amersham International [21].

\subsection{Statistical Analysis}

The obtained values are expressed as average \pm SE, using each heart $(n=9)$ as its own control. The data obtained were put under Analysis of Variance (ANOVA) with the Bonferroni correction factor using the SPSS 
12.0 program [22]. The differences were considered significant when $p$ was $\leq 0.05$.

\section{Results and Discussion}

\subsection{Synthesis Chemical}

There are several procedures for the synthesis of aromatic-derivatives [23]-[25]; nevertheless, expensive reagents and special conditions are required; therefore, in this study a new naphthalene-prazosin derivative was synthesized. It is noteworthy that prazosin was used because in their chemical structure has specific functional groups that can interact with molecules such as ethylenediamine to form a spacer arm; this compound is used to couplethearomatic derivative. Therefore, in this study the first stage was achieved by the reaction of prazosin with ethylenediamine to form the compound $3\left(\mathrm{C}_{21} \mathrm{H}_{27} \mathrm{~N}_{7} \mathrm{O}_{3}\right)$ using as boric acid as catalyst (Figure 1). The structure of compound 3 was confirmed using NMR spectroscopy (Table 1 and Table 2). The ${ }^{1} \mathrm{H}$ NMR spectrum of the compound 3 shows signals at 3.04 and $3.70 \mathrm{ppm}$ for methylene groups bound to both amino groups; at 3.56 - 3.64, 3.88 and $4.00 \mathrm{ppm}$ for pyrimidine ring; at 3.90 and $3.96 \mathrm{ppm}$ for both methoxy groups; at 6.36, 7.20 and $7.76 \mathrm{ppm}$ for protons involved in furan ring; at 6.70 for both amino groups; at 6.76 and $7.70 \mathrm{ppm}$ for phenyl group. The ${ }^{13} \mathrm{C}$ NMR spectra displays chemical shifts at 40.50 and $55.40 \mathrm{ppm}$ for both methylene groups; at 45.78, 47.60 and 158.60 - $161.18 \mathrm{ppm}$ for pyrimidine ring; at 55.50 and $55.90 \mathrm{ppm}$ for both methoxy groups; at 103.00 - 105.18 and $145.17-154.33$ ppm for phenyl group; at 113.00 - 126.92 and 145.17 - 154.33 ppm for protons involved in furan ring; at $144.50 \mathrm{ppm}$ for imino group. Finally, the presence of the naphthalene derivativewas further confirmed from mass spectrum which showed a molecular ion at $m / z$ 425.20.

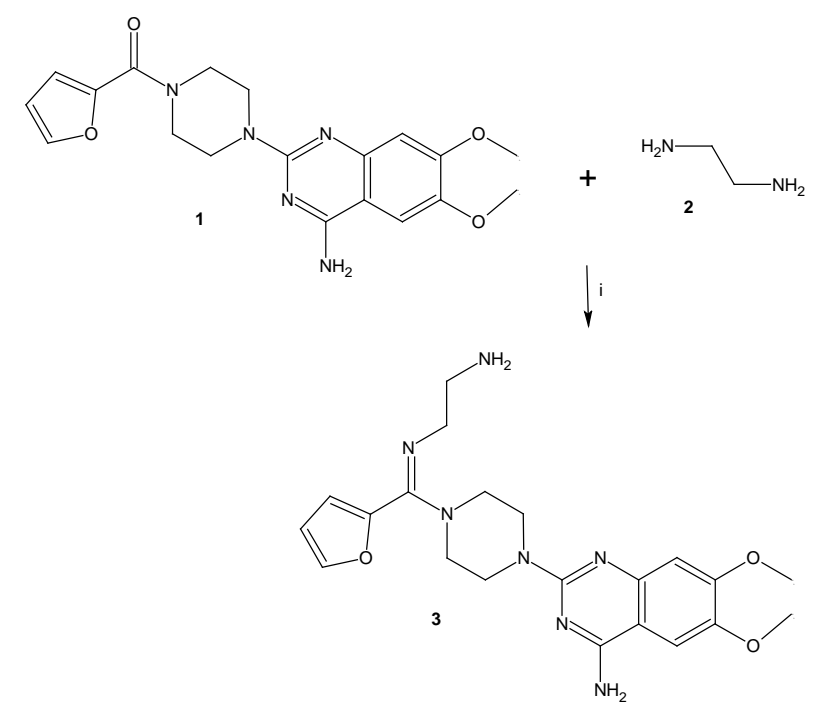

Figure 1. Sinthesis of N-1-\{[4-amino-6,7-dimethoxy-quinazolin2-yl)piperazin-1-yl]-furan-2-yl-methylene \}-ethane-1,2-diamine (3). Reaction of prazosin (1) with ethylenediamine (2) to form the compound 3. $\mathrm{i}=$ boric $\mathrm{acid} / \mathrm{rt}$.

Table 1. Spectra data of ${ }^{1} \mathrm{H}$ NMR (proton nuclear magnetic resonance; $300 \mathrm{MHz}, \mathrm{CDCl}_{3}$ ) for the compound 3.

$3.04(\mathrm{t}, 2 \mathrm{H}, \mathrm{J}=6.44 \mathrm{~Hz}), 3.56-3.64(\mathrm{~m}, 4 \mathrm{H}), 3.70(\mathrm{t}, 2 \mathrm{H}, \mathrm{J}=6.44 \mathrm{~Hz}), 3.88(\mathrm{~m}, 2 \mathrm{H}), 3.90$ (s, 3H), 3.96 (s, 3H), 4.00 (m, 2), 6.36 $(\mathrm{m}, 1 \mathrm{H}), 6.70(\mathrm{~m}, 2 \mathrm{H}), 6.36(\mathrm{~m}, 1 \mathrm{H}), 6.70$ (broad, 4H), $6.70(\mathrm{~m}, 1 \mathrm{H}), 7.20(\mathrm{~m}, 1 \mathrm{H}), 7.70(\mathrm{~m}, 1 \mathrm{H}), 7.76(\mathrm{~m}, 1 \mathrm{H}) \mathrm{ppm}$

Table 2. Spectra data of ${ }^{13} \mathrm{C}$ NMR (carbon nuclear magnetic resonance; $300 \mathrm{MHz}, \mathrm{CDCl}_{3}$ ) for the compound 3.

40.50 (C-9), 45.78 (C-13,C-15), 47.60 (C-12,C-16), 55.40 (C-8), 55.5 (C-29), 55.9 (C-31), 103.00 (C-20), 103.70 (C-26), 105.18 (C-23), 113.08 (C-3), 126.92 (C-4), 140.50 (C-6), 143.69 (C-2), 144.88 (C-5), 145.17 (C-25), 148.63 (C-19), 154.33 (C-24), 158.60 (C-17), 161.18 (C-21) ppm 
The second stage (Figure 2) was achieved by the synthesis of Compound $5\left(\mathrm{C}_{43} \mathrm{H}_{39} \mathrm{~N}_{7} \mathrm{O}_{5}\right)$ by the reaction of compound 3 with 2-hydroxy-1-naphthaldehyde using boric acid as catalyst. The structure of compound 3 was confirmed using NMR spectroscopy (Table 3 and Table 4). The ${ }^{1} \mathrm{H}$ NMR spectrum of the compound 3 shows signals at 3.50, 3.60, 3.88 and 4.00 ppm for pyrimidine ring; at 3.58 and $3.70 \mathrm{ppm}$ for methylene groups bound to both amino groups; at 3.80 and $3.90 \mathrm{ppm}$ for both methoxy groups; at 6.38, 7.20 and 7.72 for furan ring; at 6.68 - 6.90, 7.46 - 7.68 and $7.78-8.50 \mathrm{ppm}$ for phenyl groups; at 8.70 - $8.90 \mathrm{ppm}$ for imino groups; at 14.18 ppm for both hydroxyl groups. The ${ }^{13} \mathrm{C}$ NMR spectra displays chemical shifts at $45.80-47.60,162.39$ and 162.84 ppm for pyrimidine ring; at 50.08 - 52.90 for methylene groups bound to both amino groups; at 55.50 and $5.90 \mathrm{ppm}$ for both methoxy groups; at 113.18, 126.92 and $145.40 \mathrm{ppm}$ for furan ring; at 104.40 - 108.10, 120.56 -<smiles>COc1cc2nc(N3CCN(C(=NCCN)c4ccco4)CC3)nc(N)c2cc1OC</smiles><smiles>O=Cc1c(O)ccc2ccccc12</smiles><smiles>COc1cc2nc(N3CCN(C(=NCC/N=C\c4c(O)ccc5ccccc45)c4ccco4)CC3)nc(/N=C/c3c(O)ccc4ccccc34)c2cc1OC</smiles>

Figure 2. Sinthesis of 2-[4-(Furan-2yl-\{2-[(naphtalen-1-ylmethylene-amino]-ethylimino-methyl) piperazin-1-yl]-4-[(napftalen-1ylmethylene)-amino-6,7-dimethoxy-quinazolin-6,7-diol (5). Reaction of compound 3 with 2-hydroxy-1-naphthaldehyde (4) to form the compound 5.ii = boric acid/rt.

\section{Table 3. Spectra data of ${ }^{1} \mathrm{H}$ NMR (proton nuclear magnetic resonance; $300 \mathrm{MHz}, \mathrm{CDCl}_{3}$ ) for the compound 5.}

3.50 (m, 2H), 3.58 (t, 2H, J = 6.54), $3.64(\mathrm{~m}, 2 \mathrm{H}), 3.70$ (t, 2H, J = 6.54), $3.80(\mathrm{~m}, 2 \mathrm{H}), 3.90(\mathrm{~s}, 6 \mathrm{H}), 4.00$ (m, 2H), $6.38(\mathrm{~m}, 1 \mathrm{H}), 6.68$ (m, 1H), 6.82 - $6.90(\mathrm{~m}, 2 \mathrm{H}), 7.20(\mathrm{~m}, 1 \mathrm{H}), 7.46(\mathrm{~m}, 1 \mathrm{H}), 7.58$ - $7.68(\mathrm{~m}, 4 \mathrm{H}), 7.72(\mathrm{~m}, 1 \mathrm{H}), 7.78-8.44(\mathrm{~m}, 5 \mathrm{H}), 8.70$ - $8.90(\mathrm{~m}, 2 \mathrm{H})$, 14.18 (broad, 2H) ppm

Table 4. Spectra data of ${ }^{13} \mathrm{C}$ NMR (carbon nuclear magnetic resonance; $300 \mathrm{MHz}, \mathrm{CDCl}_{3}$ ) for the compound 5.

45.80 (C-24, C-26, C-15), 47.64 (C-23, C-27), 50.08 (C-8), 52.80 (C-9), 55.50 (C-52), 55.90 (C-54), 104.40 (C-35), 106.73 (C-41), 107.21 (C-38), 108.10 (C-12), 113.18 (C-3), 120.56 (C-32), 121.12 (C-18), 121.14 (C-47), 122.74 (C-20, C-49), 123.78 (C-14), 123.81 (C-43), 126.27 (C-16), 126.92 (C-4), 127.07 (C-48), 127.31 (C-19), 128. 63 (C-45), 128.86 (C-50), 129.10 (C-21), 133.96 (C-17), 136.26 (C-44), 136.50 (C-15), 136.62 (37), 137.00 (C-46), 140.50 (C-6), 143.69 (C-2), 144.90 (C-5), 151.90 (C-31), 154.06 (C-36), 159.82 (C-13), 162.39 (C-33), 162.81 (C-42), 162.84 (C-29), 163.50 (C-11), 165.00 (C-40) ppm 
126.20, 127.00 - 137.00, 151.90 - 159.82 and 162.84 ppm for phenyl groups; at 140.50, 163.50 and $165.00 \mathrm{ppm}$ for imino groups. Finally, the presence of the compound 5 was further confirmed from mass spectrum which showed a molecular ion at $\mathrm{m} / \mathrm{z} 733.30$.

\subsection{Biological Activity}

Several drugs have been used to treat the ischemia/reperfusion injury resulting from myocardial ischemia [26][28]; nevertheless, there is scarce information about the effects naphthalene derivatives on this phenomenon. Therefore, in this study the activity of a naphthalene-proposing derivative on the ischemia/reperfusion injury was evaluated.

\subsection{First Stage}

In order to evaluate the activity of the naphthalene-prazosin derivative (compound 5) on injury by ischae$\mathrm{mia} /$ reperfusion an isolated heart model was used. The results showed that the compound $\mathbf{5}$ reduced infarct size (expressed as a percentage of the area at risk) compared with vehicle-treated hearts (Figure 3). This phenomenon induced by the compound 5 could be by activation of some structure biological (p.e. ionic channels or specific receptors) involved in the endothelium of coronary artery such as happening with other compounds [29] or by the influence exerted by the compound $\mathbf{5}$ on blood pressure which could result reduction in the infarct size, and decrease the myocardial injury after ischemia-reperfusion; it is important to mention that this effect is similar to other reports for other type of drugs [30].

Analyzing this hypothesis, the activity induced by the naphthalene derivative on blood vessel capacity and coronary resistance; translated as changes in perfusion pressure was evaluated in an isolated rat heart model. The results indicate that the naphthalene derivative significantly increases the perfusion pressure over time (3 - 18 min) compared with control conditions (Figure 4). Analyzing these data and considering that part of structure as well as the functional groups involved in the chemical structure of compound $\mathbf{5}$ could be responsible for the activity exerted on perfusion pressure; in this study, the compounds 3,4 and prazosin were used such pharmacological tool.

The results showed that perfusion pressure was decreased by prazosin; however in presence of the compound 3 and 4 at a dose of $0.001 \mathrm{nM}$ the perfusion pressure was not affected. Therefore these data confirm that functional groups different involved in the compound $\mathbf{5}$ are the responsible of the activity exerted on perfusion pressure, which could result in changes in coronary resistance. To evaluate this hypothesis, the effects induced by prazosin and the compounds $\mathbf{3}, \mathbf{4}$ and $\mathbf{5}$ at a dose of $0.001 \mathrm{nM}$ on coronary resistance were evaluated (Figure 5). The results showed that coronary resistance in presence of the compound 5 was higher $(p=0.05)$ in comparison with prazosin, compounds $\mathbf{3}$ and $\mathbf{4}$ at dose of $0.001 \mathrm{nM}$ and control conditions.

On the other hand, in the search of molecular mechanism of activity induced by the compound $\mathbf{5}$ on perfusion pressure, in this study was analyzed a report, which indicates that some naphthalene-derivatives can induce changes on blood pressure via adrenergic system [10]. To evaluate these hypotheses, and analyzing the reports which indicate that prazosin interacts with $\alpha_{1}$-adrenergic receptors [13]; in this study the activity exerted by the compound 5 on left ventricular pressure in the absence or presence of prazosin was evaluated (Figure 6). The results showed that the compound 5 increases the left ventricular pressure at dose of 0.001 to $100 \mathrm{nM}$ and this effect was not inhibited by prazosin at dose of $1 \mathrm{nM}$. Also, was evaluated the effect induced by the compound 5 on left ventricular pressure in presence of metoprolol, to test whether the activity of aromatic derivative is via $\beta_{1}$-adrenergic receptors. All these data indicate that the molecular mechanism involved in the effects exerted by the compound $\mathbf{5}$ on left ventricular pressure was not through adrenergic activity.

Analyzing other reports which indicate that some drugs may induce its effect on left ventricular pressure via prostaglandins synthesis [31]; the activity exerted by the compound $\mathbf{5}$ on left ventricular pressure in the absence or presence of indomethacin $[1 \mathrm{nM}]$ was analyzed to evaluate the possibility that the activities exerted by the naphthalene derivative involve stimulation and secretion of prostaglandins. The results (Figure 7) showed that the compound 5 increased the left ventricular pressure at dose of 0.001 to $100 \mathrm{nM}$ and this effect was not blocked in presence of indomethacin. These data indicate that activity exerted by the compound $\mathbf{5}$ on left ventricular pressure was not via prostanoids synthesis and secretion.

On the other hand, other results showed that the compound 5 (Figure 8) increases the left ventricular pressure in a dose dependent manner [0.001 to $100 \mathrm{nM}$ ]; however this effect was blocked in presence of nifedipine at a 


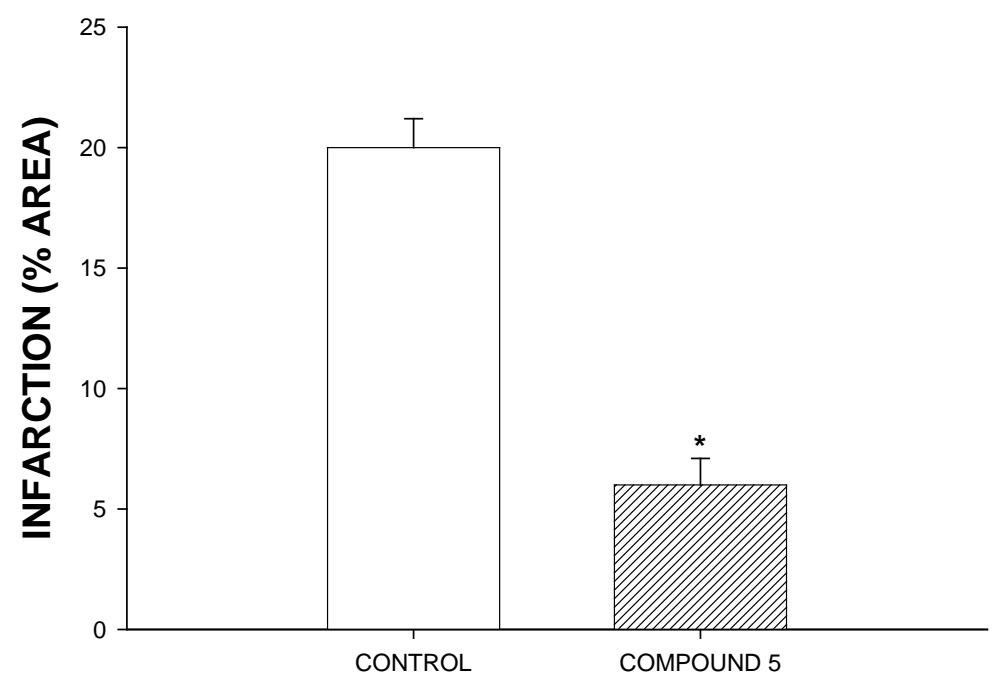

Figure 3. Effect exerted by the naphthalene-prazosinderivative (compound 5) on ischemia-reperfusion injury. The results showed that the compound 5 significantly reduced infarct size expressed as a percentage of the area at risk compared with the vehicle-treated hearts $(p=0.05)$. Each bar represents the mean \pm S.E. of 9 experiments..

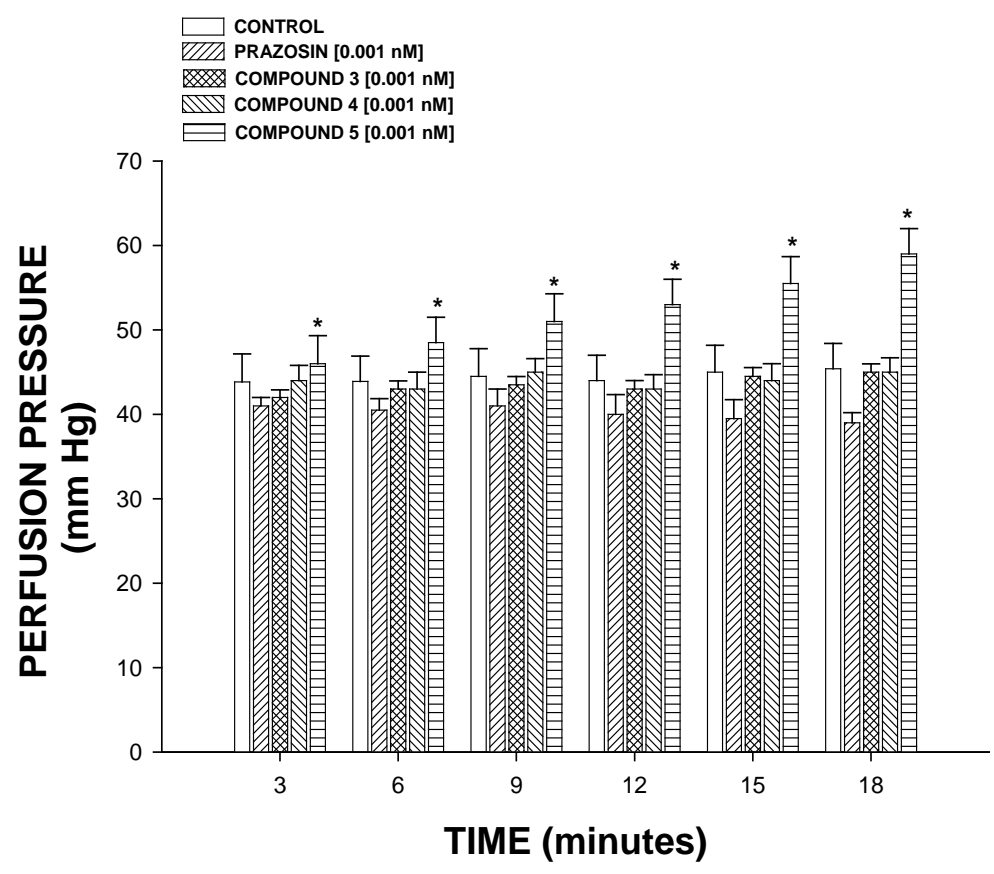

Figure 4. Effect induced by the naphthalene-prazosin derivative (compound 5) on perfusion pressure. The results show that the compound 5 significantly increase perfusion pressure $(p=0.05)$ through time in comparison with prazosin, the control conditions, the compounds 3 and 4 . Each bar represents the mean \pm S.E. of 9 experiments.

dose of $1 \mathrm{nM}$. These results suggest that activity exerted by the naphthalene derivative was via calcium channel type $\mathrm{L}$ activation. This coincides with previous studies which indicate that some compounds [32] exert their activity on left ventricular pressure through calcium channels activation

Analyzing these data and other report [33] which indicates that levosimendam exert effect on the ische- 


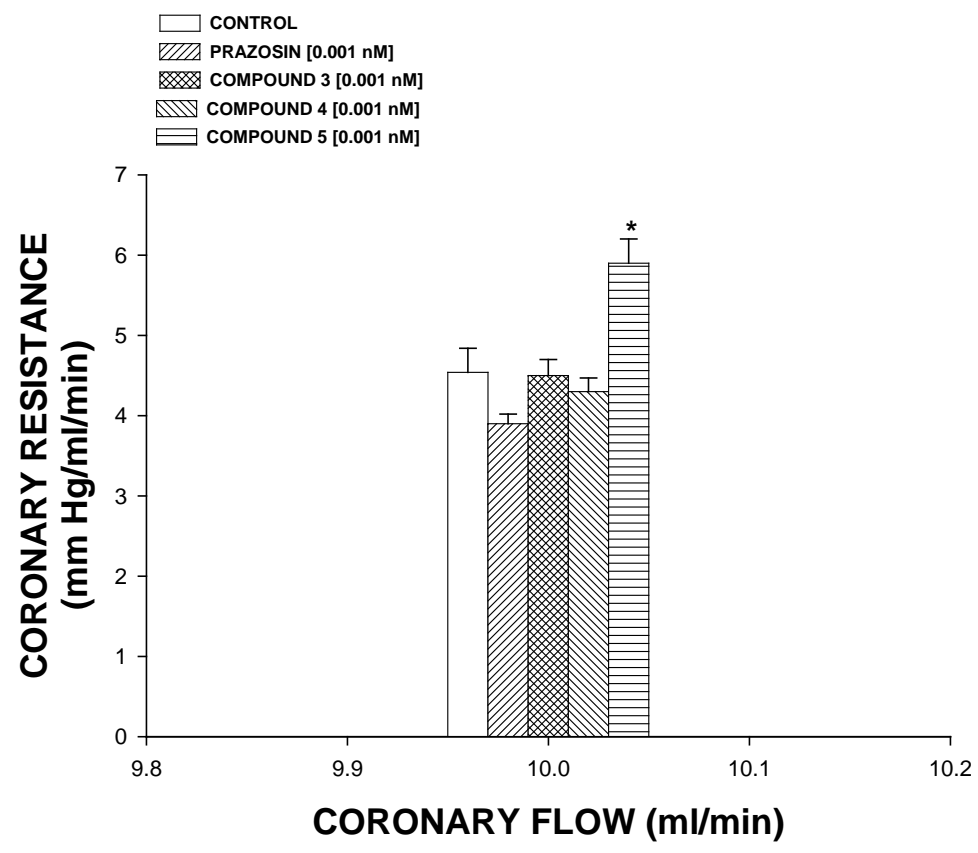

Figure 5. Activity exerted by the naphthalene-prazosin (compound 5) derivative on coronary resistance. The results show that coronary resistance was higher $(p=0.05)$ in the presence of the compound 5 in comparison with prazosin, the control conditions, the compounds 3 and 4 . Each bar represents the mean \pm S.E. of 9 experiments.

- COMPOUND 5

O COMPOUND 5 + PRAZOSIN [1 nM]

$\nabla$ COMPOUND 5 + METOPROLOL $[1 \mathrm{nM}]$

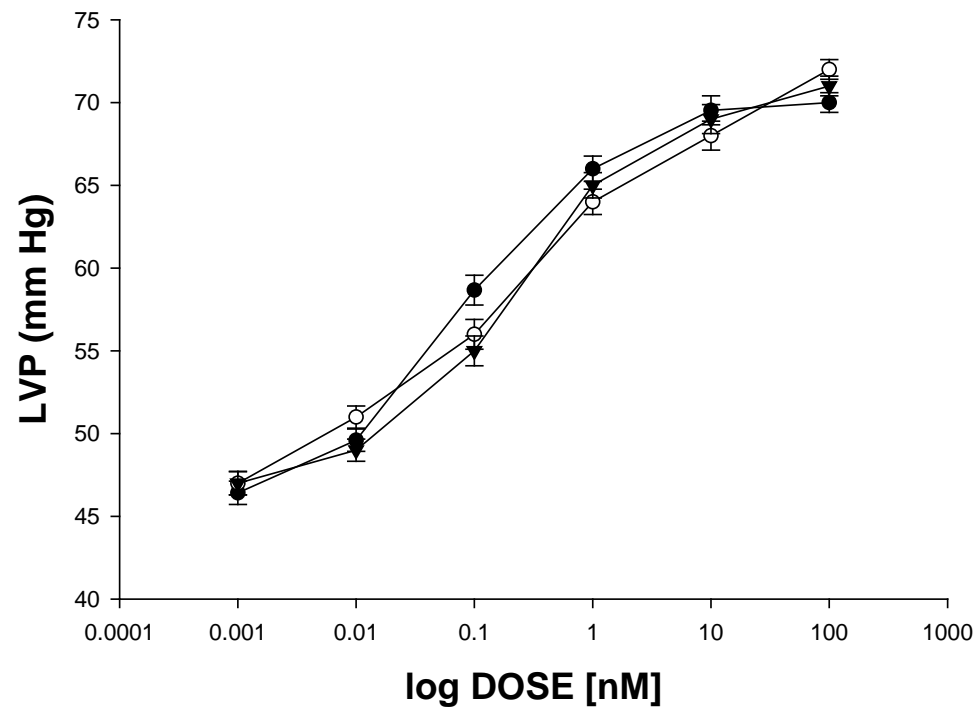

Figure 6. Activity exerted by the naphthalene-prazosin derivative (compound 5) on LVP through of adrenergic receptors. Compound 5 [0.001 to $100 \mathrm{nM}$ ] was administered (intracoronary boluses, $50 \mu \mathrm{l}$ ) and the corresponding effect on the LVP was evaluated in the absence and presence of prazosin, propranolol or metoprolol at a dose of $1 \mathrm{nM}$. The results showed that activity induced by the naphthalene-prazosin derivative on LVP was not inhibited in the presence of prazosin or metoprolol. Each bar represents the mean \pm S.E. of 9 experiments. LVP = left ventricular pressure. 


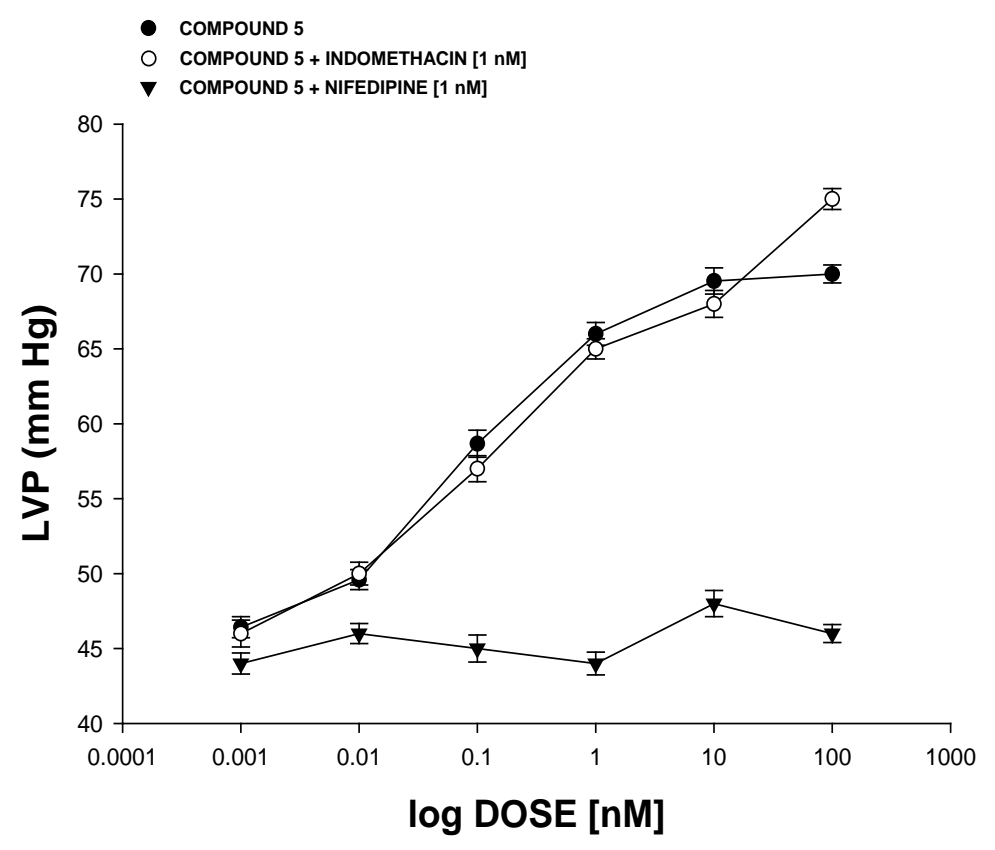

Figure 7. Effects induced by the naphthalene-prazosin derivative (compound 5) on LVP through prostaglandins synthesis or calcium channel activation. Intracoronary boluses $(50 \mu \mathrm{l})$ of the compound $5[0.001$ to $100 \mathrm{nM}]$ were administered and the corresponding effect on the LVP was determined. The results showed that compound 5increases the LVP in a dependent dose manner and this effect was not inhibited in the presence of indomethacin or nifedipine at a dose of $1 \mathrm{nM}$. Each bar represents the mean \pm S.E. of 9 experiments. LVP = left ventricular pressure.

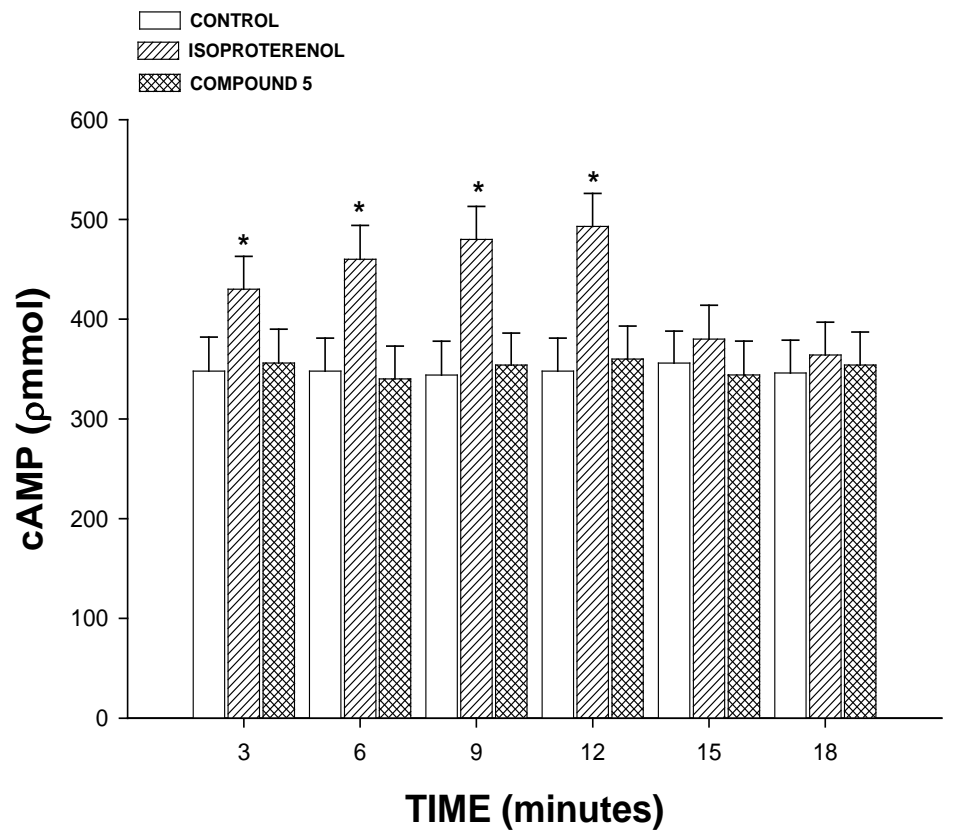

Figure 8. Effect exerted by the compound 5 and isoproterenol on cAMP levels through of time. The results show that cAMP levels was higher ( $p=$ 0.05 ) in the presence of the isoproterenol (3 - $12 \mathrm{~min}$ ) in comparison with the compound 5 and the control conditions. Each bar represents the mean \pm S.E. of 9 experiments. 
mia/reperfusion injury via changes in the concentration of calcium intracellular and cAMP; in this study, was evaluated the activity induced by the compound 5on in cAMP levels using isoproterenol as pharmacological tool. The results (Figure 8) indicate that the isoproterenol increases cAMP levels (3 to 12 minutes) compared to compound 5andcontrol conditions; however, it is important to mention that after 15 to 18minutesthe effect of isoproterenol decreased significantly; these phenomenon is similar a to other studies previously reported for isoproterenol [21] [34]. In addition, the compound 5 was not exerts effects on cAMP levels. All these data indicate; 1) The effect exerted by the isproterenolis mediated by cAMP in 3 to 12 minutes; 2) The effect of compound 5 is independent of cAMP levels.

\section{Conclusion}

Naphthalene-prazosin derivative is a particularly interesting drug, because the activity induced for this compound on injury by ischemia/reperfusion involves a molecular mechanism different in comparison with other drugs. This phenomenon may constitute a novel therapy for ischemia/reperfusion injury.

\section{Conflict of Interest}

The authors declare that they have no conflict of interest.

\section{References}

[1] Lim, G. (2012) Acute Coronary Syndromes: Reduced Mortality from MI in Denmark, England, and Poland. National Reviews of Cardiology, 9, 186. http://dx.doi.org/10.1038/nrcardio.2012.16

[2] Thygesen, K., Alpert, J. and White, H. (2007) Universal Definition of Myocardial Infarction. Journal of American College of Cardiology, 60, 2173-2195. http://dx.doi.org/10.1016/j.jacc.2012.08.001

[3] Pfeffe, M. (1995) Left Ventricular Remodeling after Acute Myocardial Infarction. Annual Review of Medicine, 46, 455-466. http://dx.doi.org/10.1146/annurev.med.46.1.455

[4] Klone, R., Przyklener, K. and Whittaker, P. (1989) Deterious Effects of Oxygen Radicals in Ischemia/Reperfusion. Circulation, 80, 1115-1127. http://dx.doi.org/10.1161/01.CIR.80.5.1115

[5] Kusumoto, K., Haist, J. and Karmazyn, M. (2001) Na(+)/H(+) Exchange Inhibition Reduces Hypertrophy and Heart Failure after Myocardial Infarction in Rats. American Journal Physiology, Heart Circulatory Physiology, 280, H738H745.

[6] Gross, E., Hsu, A. and Gross, G. (2004) Opioid-Induced Cardioprotection Occurs via Glycogen Synthase Kinase Beta Inhibition during Reperfusion in Intact Rat Hearts. Circulation Research, 94, 960-966. http://dx.doi.org/10.1161/01.RES.0000122392.33172.09

[7] Hanlon, P., Fu, P., Wright, G., et al. (2005) Mechanisms of Erythropoietin-Mediated Cardioprotection during Ischemia-Reperfusion Injury: Role of Protein Kinase C and Phosphatidylinositol 3-Kinase Signaling. The Journal of Federation of American Societies for Experimental Biology, 19, 1323-1325.

[8] Cole, W., McPherson, C. and Sontag, D. (1991) ATP-Regulated K+ Channels Protect the Myocardium against Ischemia/Reperfusion Damage. Circulation Research, 69, 571-581. http://dx.doi.org/10.1161/01.RES.69.3.571

[9] Griffiths, E. and Halestrap, A. (1993) Protection by Cyclosporin A of Ischemia/Reperfusion-Induced Damage in Isolated Rat Hearts. Journal of Molecular and Cellular Cardiology, 25, 1461-1469. http://dx.doi.org/10.1006/jmcc.1993.1162

[10] Rossoni, R., Manfredi, B. and Cavalca, V., et al. (2003) The Aminotetraline Derivative ( \pm )-(R,S)-5,6-Dihydroxy2-Methylamino-1,2,3,4-Tetrahydro-Naphthalene Hydrochloride (CHF-1024) Displays Cardioprotection in Postischemic Ventricular Dysfunction of the Rat Heart. Journal of Pharmacology and Experimental Therapeutics, 307, 633-639. http://dx.doi.org/10.1124/jpet.103.054700

[11] Sugawara, E., Nakayama, Y., Senoo, Y., et al. (1991) Protective Effects of Calmodulin Antagonists (Trifluoperazine and W-7) on Hypothermic Ischemic Rat Hearts. Acta Medica Okayama, 45, 129-134.

[12] Yang, T.-L., Chen, M.-F., Jiang, J.-L., Xie, Q.-Y., Li, Y.-P. and Li, Y.-J. (2005) The Endothelin Receptor Antagonist Decreases Ischemia/Reperfusion-Induced Tumor Necrosis Factor Production in Isolated Rat Hearts. International Journal of Cardiology, 100, 495-498. http://dx.doi.org/10.1016/j.ijcard.2004.03.051

[13] Kristek, F. and Koprdova, R. (1977) Long-Term Effect of Prazosin Administration on Blood Pressure Heart and Structure of Coronary Artery of Young Spontaneously Hypertensive Rats. Journal of Physiology and Pharmacology, 62, 295-301. 
[14] Bengtsson, C., Johnsson, G. and Regardh, C.G. (1975) Plasma Levels and Effects of Metoprolol on Blood Pressure and Heart Rate in Hypertensive Patients after an Acute Dose and between Two Doses during Long-Term Treatment. Clinical Pharmacology and Therapeutics, 17, 400-408.

[15] Blouin, M., Han, Y., Burch, J., Farand, J., Mellon, C., Gaudreault, M., et al. (2010) The Discovery of 4-\{1-[(\{2,5-Dimethyl-4-[4-(trifluorome-thyl)benzyl]-3-thienyl \}carbonyl)amino]cyclopropyl $\}$ benzoic Acid (MK-2894), A Potent and Selective Prostaglandin $\mathrm{E}_{2}$ Subtype 4 Receptor Antagonist. Journal of Medicinal Chemistry, 53, 2227-2238. http://dx.doi.org/10.1021/jm901771h

[16] Henry, P. (1980) Comparative Pharmacology of Calcium Antagonists: Nifedipine, Verapamil and Diltiazem. The American Journal of cardiology, 46, 1047-1058. http://dx.doi.org/10.1016/0002-9149(80)90366-5

[17] Bayne, K. (1996) Revised Guide for the Care and Use of Laboratory Animals Available. The Physiologist, 9, $208-211$.

[18] Figueroa-Valverde, L., Díaz-Cedillo, F., López-Ramos, M., García-Cervera, E. and Quijano-Ascencio, K. (2011) Inotropic Activity Induced by Carbamazepine-AlKyne Derivative in an Isolated Heart Model and Perfused to Constant Flow. Biomedica, 31, 232-241. http://dx.doi.org/10.7705/biomedica.v31i2.310

[19] Booth, E., Obeid, N. and Lucchesi, B. (2005) Activation of Estrogen Receptor- $\alpha$ Protects the in Vivo Rabbit Heart from Ischemia-Reperfusion Injury. American Journal of Physiology, Heart and Circulatory Physiology, 289, H2039-H2047. http://dx.doi.org/10.1152/ajpheart.00479.2005

[20] Figueroa-Valverde, L., Díaz-Cedillo, F., Díaz-Ku, E. and Camacho-Luis, A. (2009) Effect Induced by Hemisuccinate of Pregnenolone on Perfusion Pressure and Vascular Resistance Rat Heart. African Journal of Pharmacy and Pharmacology, 3, 234-241.

[21] Szokodi, I., Kinnunen, P., Tavi, P., Weckstrom, M., Toth, M. and Ruskoaho, H. (1998) Evidence for cAMP-Independent Mechanisms Mediating the Effects of Adrenomedullin, a New Inotropic Peptide. Circulation, 97, 1062-1070. http://dx.doi.org/10.1161/01.CIR.97.11.1062

[22] Hocht, C., Opezzo, J., Gorzalczany, S., et al. (1999) Una Aproxi-mación Cinética y Dinámica de Metildopa en Ratas con Coartación Aórtica Mediante Microdiálisis. Revista Argentina de Cardiologia, 67, 769-773.

[23] Weber, G. and Farris, F. (1979) Synthesis and Spectral Properties of a Hydrophobic Fluorescent Probe: 6-Propionyl-2-(dimethylamino)naphthalene. Biochemistry, 18, 3075-3078. http://dx.doi.org/10.1021/bi00581a025

[24] House, H., Koepsell, D. and Campbell, W. (1972) Synthesis of Some Diphenyl and Triphenyl Derivatives of Anthracene and Naphthalene. Journal of Organic Chemistry, 37, 1003-1011. http://dx.doi.org/10.1021/jo00972a017

[25] Yoshikawa, E. and Yoshinori, Y. (2000) Palladium-Catalyzed Intermolecular Controlled Insertion of Benzyne-Benzyne-Alkene and Benzyne-Alkyne-Alkene-Synthesis of Phenanthrene and Naphthalene Derivatives. Angewandte Chemie International Edition, 39, 173-175. http://dx.doi.org/10.1002/(SICI)1521-3773(20000103)39:1<173::AID-ANIE173>3.0.CO;2-F

[26] Node, K., Kitakaze, M., Kosaka, H., Minamino, T., Funaya, H. and Hori, M. (1977) Amelioration of Ischemia- and Reperfusion-Induced Myocardial Injury by $17 \beta$-Estradiol: Role of Nitric Oxide and Calcium-Activated Potassium Channels. Circulation, 96, 1953-1963. http://dx.doi.org/10.1161/01.CIR.96.6.1953

[27] Suparto, I., Koudy, W. and Fox, J. (2005) A Comparison of Two Progestins on Myocardial Ischemia-Reperfusion Injury in Ovariectomized Monkeys Receiving Estrogen Therapy. Coronary Artery Disease, 16, 301-308. http://dx.doi.org/10.1097/00019501-200508000-00007

[28] Jeanes, H.L., Wanikiat, P., Sharif, I. and Gray, G.A. (2006) Medroxyprogesterone Acetate Inhibits the Cardioprotective Effect of Estrogen in Experimental Ischemia-Reperfusion Injury. Menopause, 13, 80-86. http://dx.doi.org/10.1097/01.gme.0000196593.44335.eb

[29] Bouïs, D., Hospers, G. and Meijer, C. (2001) Endothelium in Vitro: A Review of Human Vascular Endothelial Cell Lines for Blood Vessel-Related Research. Angiogenesis, 4, 91-102. http://dx.doi.org/10.1023/A:1012259529167

[30] Beer, S., Reincke, M. and Kral, M. (2002) Susceptibility to Cardiac Ischemia/Reperfusion Injury Is Modulated by Chronic Estrogen Status. Journal of Cardiovascular Pharmacology, 40, 420-428. http://dx.doi.org/10.1097/00005344-200209000-00011

[31] Seillan, C., Ody, C., Russo-Marie, F. and Duval, D. (1983) Differential Aspects of Sex Steroids on Prostaglandin Secretion by Male and Female Cultured Piglet Endothelial Cells. Prostaglandins, 26, 3-12. http://dx.doi.org/10.1016/0090-6980(83)90069-2

[32] Figueroa-Valverde, L., Díaz-Cedillo, F. and López-Ramos, M. (2011) Design and Synthesis of an Estradiol Derivative and Evaluation of Its Inotropic Activity in Isolated Rat Heart. African Journal of Pharmacy and Pharmacology, 5, 1703-1712.

[33] Toit, E., Muller, C. and McCarthy, J. and Opie, L.H. (1999) Levosimendan: Effects of a Calcium Sensitizer on Func- 
tion and Arrhythmias and Cyclic Nucleotide Levels during Ischemia/Reperfusion in the Langendorff-Perfused Guinea Pig Heart. Journal of Pharmacology and Experimental Therapeutics, 290, 505-514.

[34] Ririe, D., Butterworth, J., Royster, R., McGregor, D. and Zaloga, G.P. (1995) Triiodothyronine Increases Contractility Independent of $\beta$-Adrenergic Receptors or Stimulation of Cyclic-3',5'-Adenosine Monophosphate. Anesthesiology, 82, 1004-1012. http://dx.doi.org/10.1097/00000542-199504000-00025 
Scientific Research Publishing (SCIRP) is one of the largest Open Access journal publishers. It is currently publishing more than 200 open access, online, peer-reviewed journals covering a wide range of academic disciplines. SCIRP serves the worldwide academic communities and contributes to the progress and application of science with its publication.

Other selected journals from SCIRP are listed as below. Submit your manuscript to us via either submit@scirp.org or Online Submission Portal.
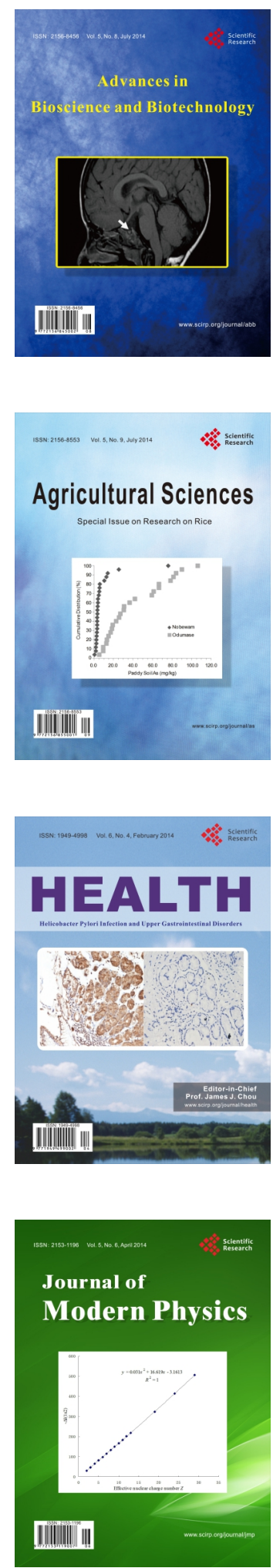
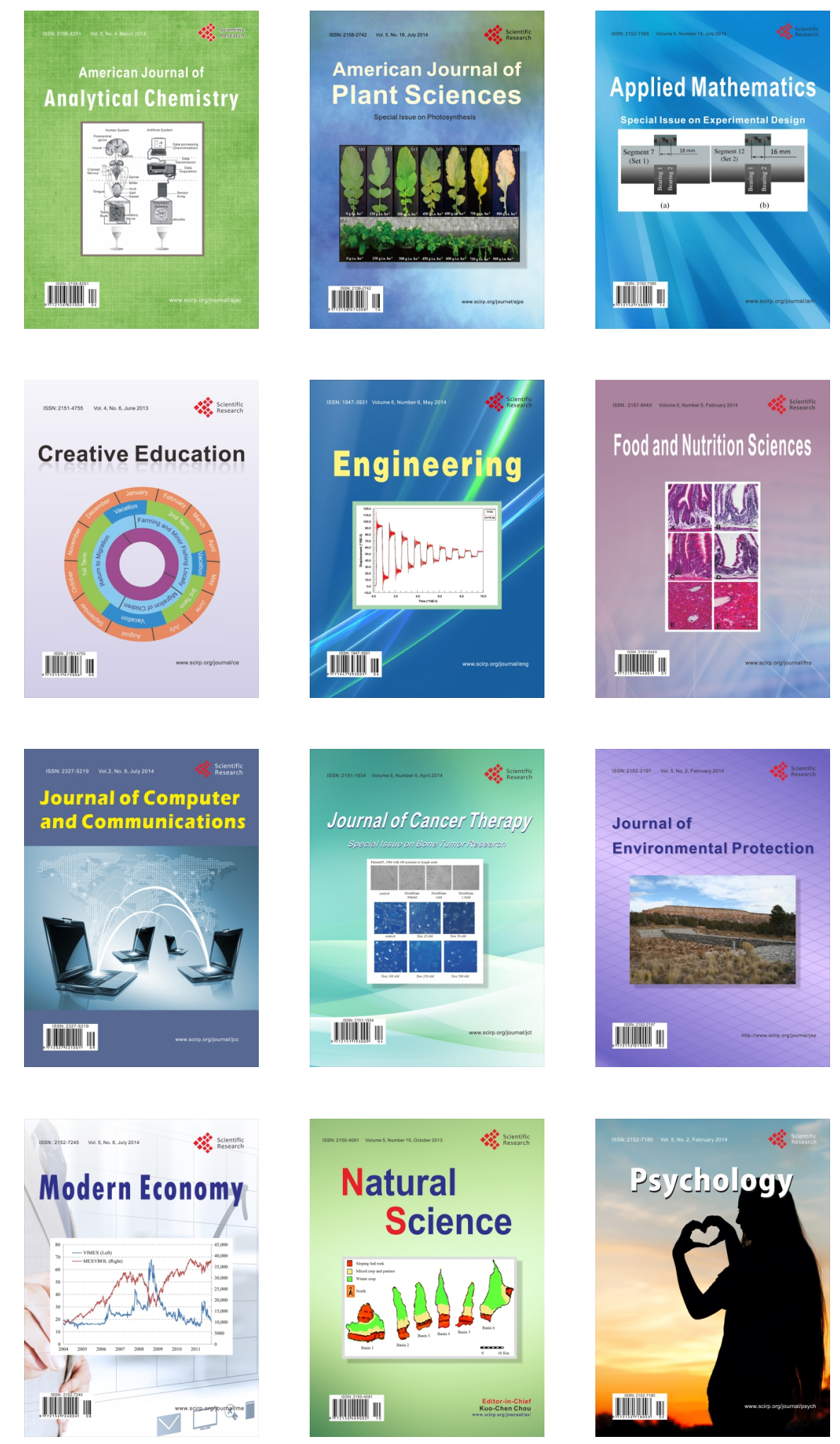